\title{
Rol de la mitocondria y el estrés oxidativo en el bloqueo del desarrollo de embriones bovinos producidos in vitro
}

\author{
Mitochondrial rol and oxidative stress in the developmental \\ blockade of in vitro produced bovine embryos \\ AM Tarazona ${ }^{a^{*}}$, M Olivera-Angel ${ }^{b}$, YY Lenis ${ }^{b}$ \\ ${ }^{a}$ Grupo de Investigación BIOGÉNESIS, Facultad de Ciencias Agropecuarias, \\ Universidad Nacional de Colombia, Sede Medellín, Colombia. \\ bBIOGÉNESIS, Facultad de Ciencias Agrarias, Universidad de Antioquia, Medellín, Colombia.
}

\begin{abstract}
SUMMARY
One of the biggest obstacles in the in vitro embryo production for basic research, commercial purposes, or conservation, is the blockade of the early cleavage, which occurs on a species-specific manner in a particular stage of development. To explain this phenomenon some causative factors have been postulated such as: disturbances in chromatin, cytoskeleton rearrangement, oxidative stress and mitochondrial damage. The latter has received considerable attention because mitochondrion is a source of reactive oxygen species (ROS), and oxidative stress is a critical mediator of physiological and pathological states. Over the past years it has been shown that hydrogen peroxide $\left(\mathrm{H}_{2} \mathrm{O}_{2}\right)$ is a pivoting molecule able to trigger cell death by different mechanisms that may or may not involve the transcription factors such as NFKB-p53, and is executed by effector caspases. It is believed that mitochondria may play an important role as a producer or as a target of $\mathrm{H}_{2} \mathrm{O}_{2}$, and as a mediator in apoptotic death of embryos. The purpose of this review is to present the state of the art about apoptosis triggered by oxidative stress and mediated by mitochondria in in vitro produced bovine embryos, as part of the explanation for the low efficiency in this process.
\end{abstract}

Palabras clave: apoptosis, NFkB, potencial transmembranal mitocondrial, p53.

Key words: apoptosis, NFאB, mitochondrial transmembranal potential, p53.

\section{INTRODUCCIÓN}

Un fenómeno comúnmente observado durante la producción de embriones in vitro es el bloqueo del desarrollo temprano, el cual ocurre en una etapa concreta del clivaje para cada especie. Se han postulado diferentes hipótesis que explican este fenómeno, las cuales involucran desórdenes en la cromatina, reorganización del citoesqueleto, estrés oxidativo y daños mitocondriales (Meirelles y col 2004).

En la última década se han desarrollado múltiples trabajos en torno al papel de la mitocondria durante el desarrollo temprano, especialmente su relación con la producción de especies reactivas de oxígeno (EROs) (Brookes 2005). Ya se ha demostrado que la cadena respiratoria de la membrana interna mitocondrial produce peróxido de hidrógeno $\left(\mathrm{H}_{2} \mathrm{O}_{2}\right)$, molécula capaz de desencadenar muerte celular mediada principalmente por $N F \kappa B$ y p53 y ejecutada por caspasas efectoras; esta ruta se ha estudiado en linfocitos como modelo de estrés oxidativo

Aceptado: 10.03.2010.

* Calle 59a\#63-20, Medellín, Bloque 50 oficina 316, Colombia; arielmarcel@gmail.com en enfermedades neurodegenerativas como Alzheimer y Parkinson (Jiménez Del Río y col 2003) y en embriones bovinos (Vélez y col 2007). Aunque el $\mathrm{H}_{2} \mathrm{O}_{2}$ ha sido asociado con el detenimiento del desarrollo embrionario temprano, los mecanismos celulares y moleculares por los cuales ocurre el detenimiento se desconocen. En este contexto, se sabe que la mitocondria está jugando un papel importante como productora o blanco del $\mathrm{H}_{2} \mathrm{O}_{2}$ y como mediadora de la muerte por apoptosis (Vélez y col 2007).

Durante el desarrollo temprano la apoptosis es un mecanismo importante para el mantenimiento de un número adecuado de células funcionales y sanas; sin embargo, existen umbrales mínimos y máximos para la presentación de apoptosis asegurando la homeostasis. Si el índice apoptótico es elevado la presencia masiva de células muertas podría dañar la homeostasis del embrión y consecuentemente detener su desarrollo y morir (Fabian y col 2005 ${ }^{\mathrm{b}}$. No obstante, el umbral de apoptosis que es detrimental para el desarrollo temprano aún no se ha establecido en las diferentes especies. Se sabe que los embriones no competentes no culminan el clivaje exitosamente y se bloquea su desarrollo entes de alcanzar el estadío de blastocisto, mientras que los competentes regulan la presentación de apoptosis y alcanzan los estadíos preimplantatorios. 


\section{BLOQUEO DEL DESARROLLO EMBRIONARIO TEMPRANO}

Los sistemas de producción de embriones in vitro simulan las condiciones del ambiente oviductal y uterino, buscando igualar las tasas de desarrollo embrionario in vivo hasta estadíos preimplantatorios (Meirelles y col 2004). Se calcula que en promedio los laboratorios pierden entre el 60 y el 70\% de los oocitos madurados in vitro, debido a que posterior a la fertilización el cigoto es incapaz de sobrellevar el clivaje exitosamente y se bloquea antes de alcanzar el estadío de blastocisto (Lequarre y col 2003). El detenimiento en el desarrollo que comúnmente sufren los embriones producidos in vitro ocurre en un estadío específico según la especie (quinto ciclo celular en conejo, cuarto en gatos, tercero en humanos, segundo en ratón); para el caso de los bovinos el detenimiento ocurre durante el cuarto ciclo celular (Memili y First 2000), es decir, en el paso del embrión de 8 a 16 células, momento que coincide además con la activación completa del genoma embrionario (De Sousa y col 1998).

Se plantea que el bloqueo de los embriones es consecuencia de la incapacidad para activar genes importantes para el desarrollo (p53, p21, Bax, Bcl-2) y del estrés producido por el ambiente alterado al cual están sometidos (temperatura, humedad, $\mathrm{pH}$, gases, etc.) (Greenwood y Gautier 2005). Por otra parte, Meirelles y col (2004) sugieren que el bloqueo no es un fenómeno pasivo, sino que requiere la participación activa de rutas de señalización que demandan la activación del genoma embrionario. La pregunta central de cuál es la causa del bloqueo se mantiene sin una respuesta clara y el fenómeno aún no está bien entendido. Sin embargo, cabe cuestionarse si este fenómeno podría estarse presentando bajo las condiciones in vitro como un mecanismo biológico para eliminar aquellos embriones que no cumplan con ciertos criterios de calidad embrionaria.

Una hipótesis es que las condiciones in vitro podrían estar afectando la dinámica de distribución y función de las mitocondrias y éstas a su vez desencadenarían apoptosis y generarían el bloqueo de los embriones bovinos (Serrano y Olivera-Angel 2003).

\section{PAPEL DE LA MITOCONDRIA EN EL DESARROLLO TEMPRANO}

Las mitocondrias son importantes para el funcionamiento celular porque producen adenosintresfosfato (ATP), regulan el ciclo de Krebs, el metabolismo de ácidos grasos, urea y ciertas hormonas, median procesos de muerte celular, regulan el balance iónico y almacenan cofactores importantes para la homeostasis (Tarazona y col 2006). En los oocitos y los embriones, las mitocondrias son esenciales para la realización de muchas de sus funciones. Acerca del desarrollo temprano el papel de las mitocondrias maternas domina sobre las paternas, ya que las mitocondrias espermáticas son ubiquitinadas y eliminadas cuando el espermatozoide ingresa al ooplasma (Jansen y col 2004). Se sabe que durante el desarrollo del oocito el número de mitocondrias varía desde unas pocas (aproximadamente 10) en las células germinales premigratorias alcanzando 200 en el estadío de oogonia. Los oocitos primarios contienen aproximadamente 6.000 mitocondrias y durante la maduración citoplásmica el número se incrementa hasta más de 100.0000 (Cummins 2004) con una o dos copias de mtADN cada una, con pocas crestas y algunas vacuolas. Después de la fertilización y durante el desarrollo temprano, las mitocondrias maduran formando nuevas crestas y además pueden aparecer en diferentes estadíos de maduración (Bavister y Squirrell 2000), sugiriendo la existencia de varias poblaciones con distintos niveles de actividad y diferentes fases de maduración (Tarazona y col 2006).

En la actualidad se han descrito algunos patrones de distribución y actividad mitocondrial en diferentes estadíos del desarrollo embrionario, y se considera que este es un importante parámetro para evaluar la competencia potencial de los oocitos y los embriones. Según Cummins (2004), se deben considerar dos aspectos en la evaluación, mitocondrial: cualitativo y cuantitativo, aspectos que han sido poco estudiados a través del desarrollo temprano de los embriones de diferentes especies como ratón (Van Blerkom y col 2002), hamster (Barnett y col 1996), bovino (Stojkovic y col 2001), primate (Bavister y Squirrell 2000) y humano (Wilding y col 2001). Hasta el momento existe solo un reporte sobre la dinámica mitocondrial completa de la actividad a través de todo el desarrollo temprano desde el oocito hasta el blastocisto en el modelo bovino in vitro (Tarazona y col 2006).

En el trabajo de Tarazona y col (2006) se evaluaron 1.816 embriones bovinos en diferentes estadíos, al igual que oocitos inmaduros y maduros, demostrando que solamente unos pocos oocitos inmaduros muestran actividad mitocondrial, debido posiblemente a que la mayoría de mitocondrias están todavía inmaduras (Wilding y col 2001) y la mayor parte de la energía es suplida "pasivamente" por las células de granulosa. También se encontró que después de la maduración in vitro de los oocitos la actividad mitocondrial aumenta y la distribución se torna difusa en el ooplasma. Aparentemente altos niveles de actividad mitocondrial son necesarios para los eventos celulares involucrados en la maduración, los cuales son dependientes de generación de ATP, tal como la maduración nuclear y la competencia meiótica, maduración del citoplasma (Picton y col 1998), rearreglo del citoesqueleto (Wang y Lessman 2002) y la acumulación de ARNms necesarios para el desarrollo temprano antes de la activación completa del genoma embrionario (Trounson y col 2001). La secuencia correcta de estos eventos y sus mecanismos no son claros aún, pero esta actividad ha sido también reportada previamente por Bavister y Squirrell (2000). Se sabe que, aunque existen otras vías para la producción de energía, el 
ATP producido por fosforilación oxidativa (OXPHOS) en la mitocondria es esencial para la supervivencia, pero el papel de las mitocondrias y los mecanismos de regulación de la actividad metabólica mitocondrial no son claros aún (Turcotte 2003).

En los embriones la segregación de mitocondrias en todos los estadíos es asimétrica, excepto en el estadío de dos células (Tarazona y col 2006). Se sabe poco de la importancia de la distribución subcelular de las mitocondrias, pero la literatura es controversial, ya que se han descrito diferentes patrones: difuso y pericitoplásmico (Tarazona y col 2006); esta descripción es contraria a la descrita por Abe y col (2002) quienes reportaron un patrón de distribución perinuclear en el desarrollo temprano, este último patrón también fue descrito por Tarazona y col (2006) pero solamente en los blastocistos expandidos. Probablemente este patrón se asocia con una actividad nuclear aumentada para la producción de ARNs, necesarios en la preparación del citoplasma para la posterior implantación embrionaria en los estadíos subsiguientes. Bowerman (2000) ha sugerido que las blastómeras pueden especializarse o polarizarse precozmente con diferentes demandas energéticas y esto explicaría los diversos patrones de distribución y segregación observados, posiblemente relacionados con los ejes de clivaje embrionario y la posterior diferenciación celular (Sardet y col 2004).

Posterior a la eclosión la distribución de las mitocondrias en las blastómeras del trofoectodermo cambia de perinuclear a pericitoplásmico, mientras que en las células de la masa interna la distribución se mantiene sin cambio (Tarazona y col 2006). Esta diferencia podría ser explicada por el hecho de que las células trofoblásticas comienzan la expresión de proteínas de adhesión y otras moléculas importantes para el reconocimiento materno-embrionario (Lu y col 2002). La reorganización citoplasmática de las blastómeras trofoectodérmicas para el reconocimiento materno-embrionario y la adhesión consume grandes cantidades de ATP y posiblemente esto contribuye a la migración de las mitocondrias cerca de la membrana plasmática, demandando más energía las células trofoblásticas que las células de la masa interna.

Los patrones de actividad mitocondrial medidos como el potencial de membrana interna están muy relacionados con la producción de EROs. En el estudio de Tarazona y col (2006) se encontró que los embriones hasta las 168 horas postinseminación (hpi) mantienen un nivel medio de actividad mitocondrial. Hasta las 50 hpi la mayoría de los embriones ( 92\%) tuvieron un nivel intermedio de actividad y solamente unos pocos $(\sim 8 \%)$ tuvieron muy poca actividad, pero a las 72 y 168 hpi hubo un cambio dramático hacia una mayor proporción de embriones exhibiendo muy bajos niveles de actividad (29\% a 72 hpi, y $69 \%$, a 168 hpi). No se encontraron embriones con alto nivel de actividad y una posible explicación ha sido recientemente propuesta, en la cual los oocitos y embriones necesitan un umbral de OXPHOS para sobrevivir y que este umbral cambia durante el movimiento del embrión hacia el útero, donde la tensión de oxígeno es menor que en el oviducto (Cummins 2004). Además Lane y Gardner (1998) sugirieron que los embriones tempranos dependen del ATP producido por la mitocondria vía lactato piruvato, pero que esta actividad disminuye después de la activación del genoma embrionario (72 hpi); durante este periodo la mayor ruta metabólica usada es la glicólisis anaeróbica (Turcotte 2003), hipótesis sustentada en parte por los hallazgos de Tarazona y col (2006) donde la actividad mitocondrial se mantuvo en un nivel "medio" hasta la activación del genoma embrionario y posteriormente disminuyó. Las mitocondrias no se dividen durante los estadíos tempranos del desarrollo embrionario, pero lo hacen después de la expansión del blastocisto, siendo estas las que proveen la energía necesaria para el clivaje temprano, manteniendo el umbral medio de actividad hasta que nuevas rutas metabólicas comiencen a operar.

Esta actividad intermedia encontrada en los embriones competentes antes de la activación del genoma posiblemente está relacionada con un sistema de protección adaptativa contra las EROs producidas por el metabolismo mitocondrial (Nohl 2005). Estas moléculas son controladas por enzimas como el glutatión o peroxidasas que han sido producidas y almacenadas durante la maduración del oocito o por transcripción permisiva durante los estadíos tempranos (Lonergan y col 2004). Así si la actividad mitocondrial fuera alta en los clivajes tempranos, el embrión moriría a causa de no poder controlar la excesiva producción de EROs.

Por lo tanto, una posible explicación para la no competencia de algunos embriones podría ser que son deficientes en su capacidad para eliminar EROs, porque no hubo acumulación o transcripción permisiva suficiente de barredores. Se evidencia la necesidad de realizar estudios de las relaciones causa-efecto por técnicas no invasivas que permitan seguir una misma muestra a través de todos los estadíos del desarrollo temprano.

Después de la activación del genoma al ingresar al útero, el embrión encuentra una concentración de oxígeno más baja, la ruta de glicólisis anaeróbica es preferida y la producción de EROs es controlada (Thompson y col 2000), lo cual es acorde con los reportes de actividad mitocondrial después de las 72 hpi cuando inicia la transcripción (Tarazona y col 2006). Otros autores también han reportado que la glicólisis anaeróbica es la principal ruta usada en el desarrollo del blastocisto (Turcotte 2003).

Estas investigaciones sugieren que durante los estadíos iniciales de desarrollo la competencia de los embriones depende de la producción mitocondrial de ATP como fue descrito por Lane y Gardner (1998), ya que los embriones no competentes tienen baja actividad mitocondrial y su clivaje es bloqueado antes de la activación del genoma. Esto evidencia un importante papel de la energía producida por la mitocondria en el proceso de activación del 
genoma. La energía en los estadíos tempranos es producida vía aminoácidos, lactato y piruvato, mientras que el exceso de producción de energía por la ruta glucolítica es nociva en estos estadíos; al parecer se requiere de un umbral mínimo de actividad mitocondrial para suplir las demandas de las blastómeras (Tarazona y col 2006). Esto está aparentemente en desacuerdo con Van Blerkom y col (2000), quienes sugirieron que los embriones no dependen solamente del ATP mitocondrial; sin embargo, estos autores no propusieron otras posibles fuentes de energía y la duda permanece sin esclarecerse.

Los embriones no competentes son incapaces de superar el bloqueo ya sea porque no logran el umbral mínimo de actividad y sus mitocondrias son insuficientes al inicio del desarrollo (Cummins 2001), o porque a pesar de que sus mitocondrias son normales, sus niveles de barredores son insuficientes para eliminar los EROs producidos por la cadena respiratoria.

Ya que la mitocondria está involucrada en la producción de EROs por la cadena respiratoria para la producción de energía, está también asociada con el balance del estado REDOX del citoplasma de las blastómeras embrionarias, pudiendo de esta forma alterar la competencia para el desarrollo temprano. Es posible que la regulación de la distribución y segregación pueda estar involucrada en la complejidad de los ejes de segmentación durante los clivajes tempranos (Sardet y col 2004).

\section{REGULACIÓN REDOX Y DESARROLLO TEMPRANO}

El uso de oxígeno como sustrato para la producción de energía en los sistemas aeróbicos resulta también en la producción de EROs, particularmente el anión superóxido y el radical hidroxilo. Las EROs son aceptores de electrones altamente activos y son capaces de capturar electrones de otras moléculas transformándolas en radicales libres. El peróxido de hidrógeno $\left(\mathrm{H}_{2} \mathrm{O}_{2}\right)$ no es un radical per se, pero es un producto de una reacción de tipo catálisis por ión metálico del anión superóxido; tanto el $\mathrm{H}_{2} \mathrm{O}_{2}$ como el anión superóxido pueden formar el radical hidroxilo, el cual es muy reactivo (Harvey 2002).

Las EROs son producidas principalmente a través de la cadena de transporte de electrones en la membrana interna mitocondrial, pero también son producidas en el citoplasma por la NADPH-oxidasa unida a membrana, por la enzima citocromo $\mathrm{p} 450 \mathrm{y}$ por el sistema xantina-xantina oxidasa (Mostefai y col 2008). Las células poseen diversos mecanismos para contrarrestar el efecto de las EROs, entre los cuales se encuentran los sistemas de catalasas, peroxidasas y superóxido dismutasas dependientes de $\mathrm{Cu}, \mathrm{Zn}$ y $\mathrm{Mn}$, algunas de las cuales presentan transcripción permisiva durante el desarrollo temprano previo a la activación del genoma (Harvey 1995).

Se sabe que tanto el estado de oxidorreducción celular como el metabolismo son cambiantes a lo largo del desarrollo embrionario temprano y es diferente entre las especies. Durante el paso hacia el estadío de blastocisto ocurre un cambio de fosforilación oxidativa a glicólisis anaeróbica como fuente de ATP, indicando que los estadíos preimplantatorios requieren un estado más oxidado que reducido, favoreciendo la adaptación al medio uterino, el cual es más hipóxico que el oviductal (Harvey 2002). Las altas tensiones de $\mathrm{O}_{2}$ (aproximadamente 20\%) en los cultivos in vitro podrían estar ocasionando una excesiva producción de EROs y la muerte embrionaria temprana. El papel de las EROs durante el desarrollo temprano es controversial, debido a que los resultados han sido diversos cuando se induce la producción de EROs o se aplican antioxidantes en los medios (Thompson y col 1996).

Las mitocondrias generan EROs en la cadena respiratoria pero el mecanismo exacto aún no se ha dilucidado. Una hipótesis sugiere que el primer sitio de producción es el complejo I, que puede generar el radical superóxido vía reducción del oxígeno por el centro hierro-azufre $\left(\mathrm{N}_{2}\right)$ del complejo y $\mathrm{H}_{2} \mathrm{O}_{2}$ de una forma independiente del potencial de membrana. Otro sitio de producción sería el citocromo oxidasa del complejo III, que puede generar radical superóxido vía ubisemiquinona y $\mathrm{H}_{2} \mathrm{O}_{2}$ solamente si el potencial de membrana es alto (Nohl y col 2005). Otra hipótesis es que el flavinmononucleótido (FMN) en el complejo I sería la fuente de $\mathrm{H}_{2} \mathrm{O}_{2}$. El sitio exacto de generación de EROs por la mitocondria se mantiene aún sin esclarecer, ya que el superóxido producido por la cadena transportadora de electrones es transformado inmediatamente a $\mathrm{H}_{2} \mathrm{O}_{2}$ por la superoxidodismutasa Mn (Mn SOD), este último es el que se mide como indicador de la producción de EROs (Kowaltowski y col 2001). Las EROs cumplen funciones como participar en rutas de señalización, pero también pueden generar estados patológicos o conducir a la muerte celular (Liu y col 2002).

\section{APOPTOSIS DURANTE EL DESARROLLO TEMPRANO}

El término apoptosis hace referencia a un proceso de muerte celular programada que se reconoce por una morfología nuclear específica que la diferencia de la necrosis (Kerr y col 1972). La apoptosis se caracteriza por: contracción y aumento en la densidad celular, cromatina picnótica y empaquetada en fragmentos distribuidos en la periferia nuclear, el ADN se hidroliza en fragmentos de aproximadamente 185 pb debido al clivaje específico ejecutado entre los nucleosomas y es un proceso bajo control genético (Majno 1995).

La apoptosis en los embriones se ha convertido en una temática importante de investigación, debido a que se ha planteado su posible papel en la respuesta celular al estrés ambiental y las condiciones subóptimas para el desarrollo in vitro (Betts y col 2001). Sin embargo, esta ocurre de forma fisiológica durante el desarrollo temprano 
(Milligan y Schwartz 1997) y su principal función es la de eliminar las células defectuosas y controlar la población celular (Jacobson y col 1997, Fabian y col 2005a). Un conocimiento detallado de las características de la apoptosis durante el desarrollo temprano es necesario para implementar medidas que conduzcan al mejoramiento de la calidad y supervivencia de los embriones producidos in vitro, debido a que el aumento en el índice apoptótico es un indicador de manejo inadecuado de las condiciones in vitro (Rubio y col 2005).

Las posibles causas de apoptosis durante el desarrollo temprano son: anormalidades cromosomales y nucleares (Hardy 1999), inapropiado potencial de desarrollo (incompetencia), desbalance hormonal y de factores de crecimiento (Fabian y col 2005a) y exposición a factores nocivos como EROs (Yang y col 1998), irradiación UV (Zhou y Steller 2003) o choque térmico (Paula-Lopesa y Hansen 2002).

El proceso apoptótico puede desencadenarse por dos vías: la extrínseca que involucra receptores de muerte y la intrínseca mediada por la mitocondria. Durante la apoptosis la permeabilidad de la membrana mitocondrial se incrementa, permitiendo la salida del citocromo c para la formación del complejo apoptosoma que conllevan a la cascada de activación de caspasas 3, 9 y efectoras que conducen a la muerte celular (Little y Mirkes 2002). Aparte del papel pivotante de la mitocondria en la ejecución de la apoptosis, las EROs producidas por la cadena respiratoria podrían estar involucradas en la inducción de la misma (Fleury 2002).

\section{MODELO DE APOPTOSIS MEDIADO POR EROs}

Debido a que el estrés oxidativo es un factor importante en el bloqueo del desarrollo temprano in vitro y que el peróxido es producido endógenamente por los embriones, la ruta apoptótica inducida por $\mathrm{H}_{2} \mathrm{O}_{2}$ podría explicar en parte el detenimiento del ciclo celular que sufren los embriones bovinos (Tarazona y col 2006) (figura 1).

Se ha comprobado que el $\mathrm{H}_{2} \mathrm{O}_{2}$ media la apoptosis en linfocitos de sangre periférica por un mecanismo que puede estar mediado por factores de transcripción como $N F \kappa B, p 53$ y c-Jun (Jiménez del Río y col 2002). Se sabe que hay una proteína tirosina quinasa $S y K$ que activada por $\mathrm{H}_{2} \mathrm{O}_{2}$ es la responsable de la fosforilación que provoca la inhibición de $I k B \alpha$, a su vez responsable de mantener inactivo a $N F \kappa B$ en el citoplasma (Takada 2003) (figura 1). Sin embargo, este modelo no aplica para los embriones bovinos, donde el $\mathrm{H}_{2} \mathrm{O}_{2}$ media apoptosis de forma independiente de estos factores de transcripción (Vélez y col 2007).

Tanto $p 53$ como $N F \kappa B$ son factores de transcripción importantes en la regulación de la apoptosis. Al parecer existe una comodulación entre ambos factores de transcripción, pudiendo mutuamente aumentar o disminuir su actividad.
FACTOR DE TRANSCRIPCIÓN P53

El factor $p 53$ es una molécula ubicua que participa en diversas funciones celulares como: regulación del ciclo celular, diferenciación, reparación del ADN, envejecimiento, recombinación y apoptosis (Favetta y col 2004). Aunque es un factor de transcripción cuenta con una actividad propia para mediar rutas como la apoptosis intrínseca (Jiménez del Río y Vélez 2002). Se sabe que es capaz de activar o represar por lo menos 100 genes estudiados, sin embargo, los análisis de bioinformática sugieren que la cifra podría superar los 4.000 (Lu 2005). Esto indica la gran importancia de este factor para el mantenimiento de una relación mitosis/ apoptosis adecuada.

Para cumplir con sus múltiples funciones el $p 53$ es regulado a nivel de transcripción y traducción, también sufre varias modificaciones postransduccionales como fosforilación, acetilación, metilación y glicosilación. Como mediador de la reparación del ADN el $p 53$ favorece la transcripción de $G A D D 45, p 48, p 53 R 2, A P E 1$ y pol- $\beta$, influyendo así en la reparación por excisión de bases (Hofseth 2004).

Como regulador de la muerte celular programada puede participar tanto en la vía apoptótica extrínseca (mediando transcripción de receptores de muerte) como en la vía apoptótica intrínseca (mediando transcripción de factores pro y antiapoptóticos o induciendo directamente la apertura del poro de transición mitocondrial) (Vousden 2002) (figura 1). Por ser guardián del ciclo celular se considera fundamental en los procesos de desarrollo temprano. Las mutaciones sobre $p 53$ lo pueden convertir en un oncogen, favoreciendo la replicación celular no controlada ( $\mathrm{Lu}$ 2005), lo mismo ocurre cuando es bloqueado de forma irreversible (Vélez y col 2007).

\section{FACTOR DE TRANSCRIPCIÓN $N F \kappa B$}

El $N F \kappa B$ está presente en estado de reposo en el citoplasma de todas las células, consiste de una familia de proteínas que contienen el dominio Rel y a su vez están inhibidas por una familia de proteínas que contienen un dominio de anclaje, entre estas últimas se encuentran

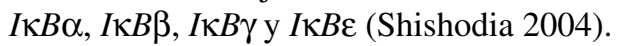

El $N F \kappa B$ se considera un factor de transcripción que puede actuar en dos vías antagónicas, ya que la dirección de sus efectos dependerá del momento en el ciclo celular, el grado del estímulo y el ambiente intra y extracelular (Shishodia 2004). Participa en la regulación del ciclo celular produciendo factores de proliferación como citoquinas y también en la muerte celular produciendo factores tanto proapoptóticos (c-myc, Fas) como antiapoptóticos (IAP, proteínas de la familia $\mathrm{Bcl}$-2) (figura 1).

La expresión de $N F \kappa B$ durante el desarrollo temprano indica que este se requiere para responder a estímulos ambientales o estrés intracelular, se ha sugerido que la 


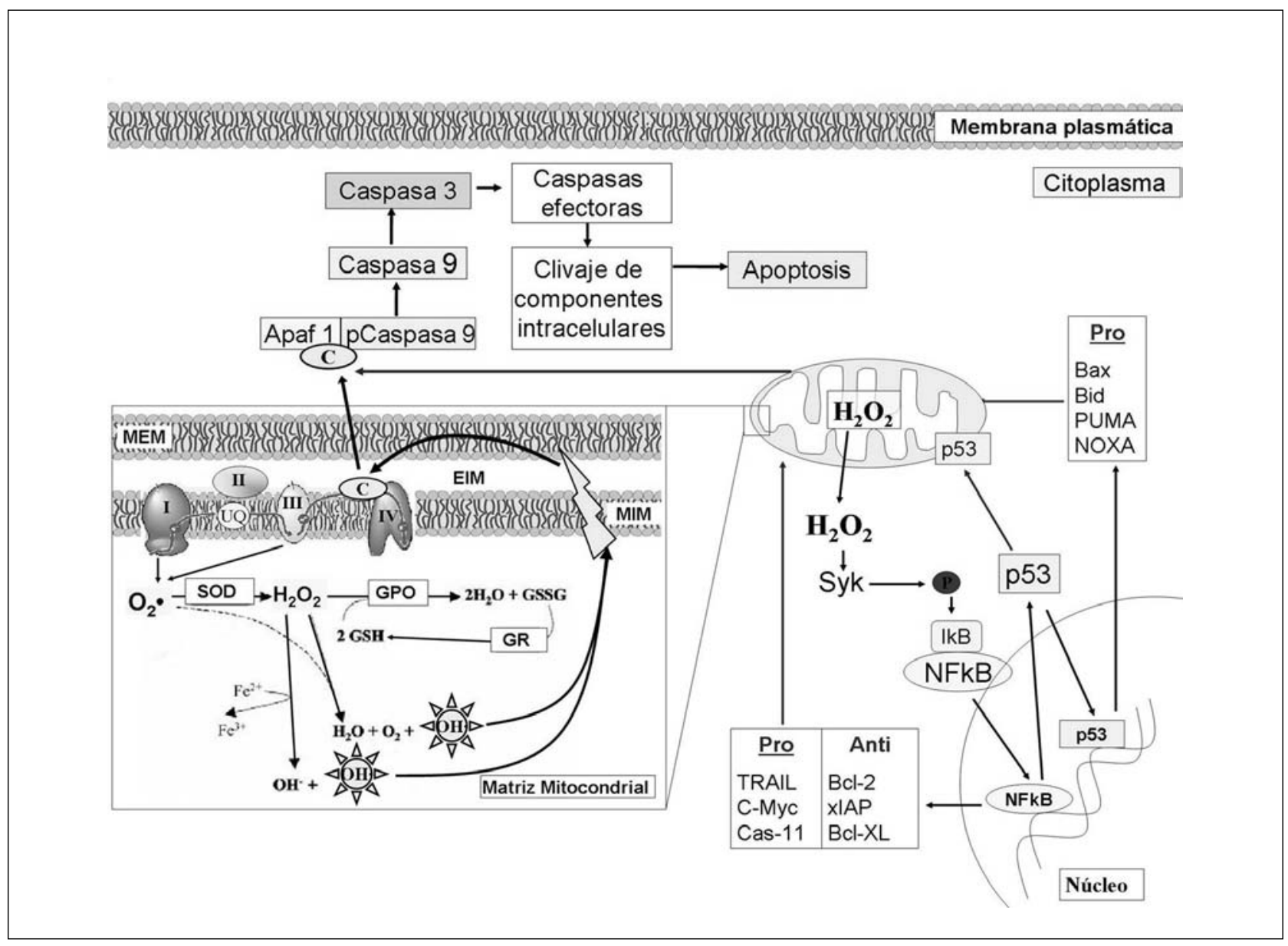

Figura 1. Ruta de señalización de apoptosis mediada por estrés oxidativo y mitocondria. (Adaptado y modificado de Parone y col 2002 , Fleury y col 2002, Susin y col 1996). Anti: factores antiapoptóticos; C: citocromo c; EIM: espacio intermembranal; Fe: Hierro; GPO: glutatión peroxidasa oxidado; GR: glutatión reducido; GSH: glutatión; GSSG: glutatión oxidado; $\mathrm{H}_{2} \mathrm{O}_{2}$ : peróxido de hidrógeno; I, II, III, IV: complejos de la cadena respiratoria; MEM: membrana externa mitocondrial; MIM: membrana interna mitocondrial; $N F \kappa B$ : factor de transcripción nuclear kappa B; P53: factor de transcripción p53; Pro: factores proapoptóticos; SOD: Superoxidodismutasa; UQ: ubiquinona.

El peróxido producido por la mitocondria puede desencadenar apoptosis por varios mecanismos que pueden involucrar o no la activación de factores de transcripción, capaces de regular la viabilidad celular a través de la expresión de genes tanto pro como antiapoptóticos. Sea cual sea la vía, el citocromo c sale de la membrana externa mitocondrial y forma el complejo apoptosoma junto con la procaspasas-9 y el Apaf-1, finalmente la apoptosis es desencadenada y ejecutada por caspasas efectoras. y col 1996).

Apoptosis signaling pathway mediated by oxidative stress and mitochondria. (Adapted from Parone y col 2002, Fleury y col 2002, Susin

The peroxide produced by mitochondria can trigger apoptosis by several mechanisms that may or may not involve the activation of transcription factors, they are able to regulate cell viability through gene expression of both pro, and antiapoptotic. Whatever the way, cytochrome c are released from mitochondrial outer membrane and forms the apoptosome complex with procaspase- 9 and Apaf-1, then apoptosis is triggered and executed by effector caspases.

activación de $N F \kappa B$ en el estadío de una célula en los embriones de ratón es necesaria para el progreso en la segmentación y desarrollo de los estadíos subsiguientes. En embriones bovinos el uso de bloqueadores de $N F \kappa B$ demostró que es esencial en la regulación del clivaje (Vélez y col 2007). La relación de $N F \kappa B$ con las EROs es incierta, pero se sabe que el estrés oxidativo es capaz de mediar su activación como factor de transcripción (Jiménez del Río y col 2002).

\section{APOPTOSIS POR $\mathrm{H}_{2} \mathrm{O}_{2}$ EN EMBRIONES BOVINOS}

Existe asociación entre la acumulación de $\mathrm{H}_{2} \mathrm{O}_{2}$ y la presentación de apoptosis en los embriones bovinos. Sin embargo, los embriones no competentes muestran un potencial transmembranal mitocondrial (PTM) muy bajo como para producir el peróxido vía mitocondrial (Vélez y col 2007). Con relación a estos resultados, se han generado dos hipótesis para explicar este fenómeno: 
1) $\mathrm{El} \mathrm{H}_{2} \mathrm{O}_{2}$ es producido por el alto potencial mitocondrial (Nohl y col 2005) durante la maduración del oocito, y aquellos embriones que son capaces de barrer el $\mathrm{H}_{2} \mathrm{O}_{2}$ progresan en el clivaje sincrónicamente (embriones competentes), aquellos que no son capaces de barrerlo lo acumulan y se bloquean en el cuarto ciclo celular (embriones no competentes); 2) Los altos índices de $\mathrm{H}_{2} \mathrm{O}_{2}$ que presentan los embriones no competentes pueden producirse de una forma independiente del PTM por fallas en la cadena respiratoria (Cadenas y Davies 2000). De esta forma el $\mathrm{H}_{2} \mathrm{O}_{2}$ acumulado por los embriones no competentes podría ser una de las causas del bloqueo temprano y de la presentación de apoptosis.

Los embriones no competentes acumulan $\mathrm{H}_{2} \mathrm{O}_{2}$ y muestran los más bajos niveles de PTM, además presentan un elevado índice de caspasas activas que conducen a la apoptosis y al bloqueo del desarrollo (Tarazona y col 2006, Vélez y col 2007). Esto sugiere que la apoptosis es mediada por el $\mathrm{H}_{2} \mathrm{O}_{2}$ acumulado y es ejecutada por caspasas. Contrariamente, los embriones competentes no presentan acumulación de $\mathrm{H}_{2} \mathrm{O}_{2}$, probablemente porque el $\mathrm{H}_{2} \mathrm{O}_{2}$ producido por los niveles intermedios de PTM es barrido por los limpiadores producidos y de esta forma controlado, y así, se presenta un índice apoptótico que se supone normal para la formación del blastocele y el control de calidad de células defectuosas (Tarazona y col 2006, Vélez y col 2007). Lo anterior demuestra una clara diferencia en la actividad mitocondrial y producción de $\mathrm{H}_{2} \mathrm{O}_{2}$ entre los embriones competentes y no competentes (Tarazona y col 2006).

Se ha comprobado que el $\mathrm{H}_{2} \mathrm{O}_{2}$ es capaz de inducir la activación de $N F \kappa B$ como factor de transcripción proapoptótico (Takada y col 2003). Sin embargo, para el caso de los embriones bovinos, se ha demostrado que el bloqueo de este factor de trascripción es detrimental para el desarrollo embrionario, lo que sugiere que durante el desarrollo temprano el $N F \kappa B$ tiene otras funciones diferentes al inicio de la muerte celular programada por apoptosis (Vélez y col 2007). Esta hipótesis se sustenta en los hallazgos realizados por Nishikimi y col 1999, quienes reportaron que una de las subunidades del $N F \kappa B$, el $R E L A$, se expresa en los oocitos y embriones de ratón durante todo el desarrollo temprano, pero su ubicación nuclear solo se demostró en el estadío de cigoto. Las células trofoblásticas expresan tanto p52/p100 como RelA (subunidades del $N F \kappa B$ ), lo que indica una diferencia de expresión dependiente del estadío de desarrollo y del tipo celular (Torchinsky y Toder 2004).

Los hallazgos de Vélez y col (2007) sugieren un papel más complejo del $N F \kappa B$ durante el desarrollo temprano, ya que al bloquearlo los embriones presentaron una segmentación asimétrica que difiere del patrón de segmentación de los mamíferos que es simétrico rotacional, pero que no correspondió con proliferación ni con muerte celular excesivas.

En el caso de $p 53$ que también está involucrado en la mediación de apoptosis por $\mathrm{H}_{2} \mathrm{O}_{2}$, cuando este es bloqueado en los embriones estos comprometen su viabilidad e inician un proceso de división descontrolada (Vélez y col 2007). Aunque uno de los papeles más conocidos de $p 53$ es su función clave dentro de las rutas de respuesta a condiciones de estrés celular, en los embriones bovinos parece no estar involucrado en el proceso de detenimiento del ciclo celular. En la hipótesis planteda por Vélez y col (2007), el $\mathrm{H}_{2} \mathrm{O}_{2}$ generaría apoptosis ejecutada por caspasas; sin embargo, cuando se bloqueó la caspasa 3 de forma irreversible se observó una segmentación acelerada de los embriones. Previos estudios han demostrado que la inhibición generalizada de las caspasas es nociva para el desarrollo embrionario temprano y recientemente se ha planteado que las caspasas podrían tener otras funciones diferentes a su bien conocida función como ejecutoras de la muerte celular por apoptosis; sin embargo, aún no es claro cuáles podrían ser esas funciones (Zakeri y col 2005).

\section{CONCLUSIÓN}

A pesar de que la técnica de producción de embriones bovinos in vitro lleva más de dos décadas, las tasas de producción y la calidad de los embriones aún no son lo suficientemente altas para cubrir las necesidades en los campos de la investigación y la reproducción asistida. El detenimiento del clivaje durante el desarrollo temprano del embrión es la principal causa de esta baja eficiencia. Esta revisión muestra que el estrés oxidativo es uno de los mediadores del bloqueo y que la mitocondria es la organela directamente implicada en este proceso. Un nivel mínimo de actividad mitocondrial podría regular la competencia embrionaria para alcanzar el estadío de blastocisto, lo que evidencia que la mitocondria es la principal organela para la regulación del balance REDOX y por ende fundamental en los procesos fisiológicos que regulan el desarrollo embrionario temprano. Las fallas en la funcionalidad mitocondrial conllevan a que los embriones produzcan y acumulen $\mathrm{H}_{2} \mathrm{O}_{2}$ que desencadenaría la muerte celular por apoptosis y los haría no competentes para alcanzar el estadío de blastocisto. Esta apoptosis es ejecutada por caspasas de una forma independiente de $N F \kappa B$ y $p 53$ a diferencia de otros modelos celulares, lo que sugiere que los embriones cuentan con mecanismos de regulación alternativos para la supervivencia o muerte celular. El estrés oxidativo por $\mathrm{H}_{2} \mathrm{O}_{2}$ es una de las causas del detenimiento y muerte de los embriones bovinos producidos in vitro. Sin embargo, se evidencian múltiples vacíos en el conocimiento de las rutas celulares y moleculares de regulación del desarrollo embrionario temprano y de muerte o supervivencia, por lo cual se sugiere realizar nuevas investigaciones encaminadas a dilucidar estos vacíos y se permita una mayor comprensión de la complejidad de estos fenómenos biológicos.

A la luz de los resultados mostrados en la literatura, se sugiere evaluar los protocolos de producción de embriones y modificarlos de tal manera que se favorezca la capacidad del embrión para contrarrestar los efectos nocivos del ambiente 
oxidante, y les permita lograr la competencia morfológica y funcional necesarias para alcanzar los estadíos preimplantatorios. Aunque se han realizado estudios enfocados a la resolución de este problema, los resultados son controversiales y poco satisfactorios, por lo que se evidencia la necesidad de nuevas investigaciones en esta área.

\section{RESUMEN}

Uno de los mayores obstáculos en la producción de embriones in vitro con fines de investigación básica, comerciales, o de conservación, es el detenimiento temprano del clivaje que ocurre de forma específica en una etapa del desarrollo. Para explicar este fenómeno se han postulado diferentes factores causales como: desórdenes en la cromatina, rearreglos del citoesqueleto, estrés oxidativo y daños mitocondriales. Esta última propuesta ha recibido gran atención, debido a que la mitocondria es fuente de especies reactivas de oxígeno (EROs) y el estrés oxidativo es un mediador crítico de procesos fisiológicos y estados patológicos. Durante los últimos años se ha demostrado que el peróxido de hidrógeno $\left(\mathrm{H}_{2} \mathrm{O}_{2}\right)$ es una molécula pivotante capaz de desencadenar muerte celular por diferentes mecanismos que pueden involucrar o no a los factores de transcripción: $N F \kappa B$ - p53, y es ejecutado por caspasas efectoras Se cree que la mitocondria podría estar jugando un papel importante como productora o como blanco del $\mathrm{H}_{2} \mathrm{O}_{2}$, y como mediadora en la muerte por apoptosis de los embriones. El objetivo de esta revisión es mostrar el estado del arte en cuanto a la apoptosis desencadenada por estrés oxidativo y mediada por la mitocondria en los embriones bovinos producidos in vitro, como parte de la explicación del bloqueo del clivaje y la baja eficiencia que aún se tiene en este proceso.

\section{REFERENCIAS}

Abe H, S Matsuzaki, H Hoshi. 2002. Ultrastructural differences in bovine morulae classified as high and low qualities by morphological evaluation. Theriogenology 57, 1273-1283.

Barnett DK, J Kimura, BD Bavister. 1996. Translocation of active mitochondria during hamster preimplantation embryo development studied by confocal laser scanning microscopy. Dev Dynam 205, 64-72.

Bavister BD, JM Squirrell. 2000. Mitochondrial distribution and function in oocytes and early embryos. Hum Reprod 15, 189-198.

Betts DH, WA King. 2001. Genetic regulation of embryo death and senescence. Theriogenology 55, 171-191.

Bowerman B. 2000. Embryonic polarity: Protein stability in asimmetric cell division. Curr Biol 10, 637-641.

Brookes P. 2005. Mitochondrial H (+) leak and ROS generation: an odd couple. Free Radic Biol Med 38, 12-23.

Cadenas E, K Davies. 2000. Mitochondrial free radical generation, oxidative stress, and aging. Free Radic Biol Med 29, 222-230.

Cummins J. 2001. Cytoplasmic inheritance and its implications for animal biotechnology. Theriogenology 55, 1381-1399.

Cummins J. 2004. The role of mitochondria in the establishment of oocyte functional competence. Eur J Obstet Gynecol Reprod Biol $115,23-29$

De Sousa PA, AJ Watson, RM Schultz. 1998. Transient expression of a translation initiation factor is conservatively associated with embryonic gene activation in murine and bovine embryos. Biol Reprod 4, 969-977.

Fabian D, J Koppel, P Maddox-Hyttel. 2005 a . Apoptotic processes during mammalian preimplantation development. Theriogenology 64, 221-231.

Fabian D, JO Gjorret, F Berthelot, F Martinat-Botte, P Maddox-Hyttel. $2005^{\mathrm{b}}$. Ultrastructure and cell death of in vivo derived and vitrified porcine blastocysts. Mol Reprod Dev 70, 155-165
Favetta L, C Robert, W King, D Betts. 2004. Expression profiles of p53 and p66shc during oxidative stress-induced senescence in fetal bovine fibroblasts. Exp Cell Res 299, 36-48.

Fleury C, B Mignotte, J Vayssiere. 2002. Mitochondrial reactive oxygen species in cell death signalling. Biochimie 84, 131-141.

Gary DS. 2001. In vitro maturation of oocytes. Current Women's Health Reports, 143-151.

Greenwood J, J Gautier. 2005. From oogenesis through gastrulation: developmental regulation of apoptosis. Semin Cell Dev Biol 16, 215-224.

Hardy K. 1999. Apoptosis in the human embryo. Reviews of Reproduction 4, 125-134.

Harvey M, M Arcellana-Panlilio, X Zhang, G Schultz, A Watson. 1995. Expression of genes encoding antioxidants enzymes in preimplantation mouse and cow embryos and primary bovine oviduct cultures employed for embryo coculture. Biol Reprod 53, 532-540.

Harvey A, K Kind, J Thompson. 2002. REDOX regulation of early embryo development. Reproduction 123, 479-486.

Hofseth LJ, SP Hussain, CC Harris. 2004. p53: 25 years after its discovery. Trends Pharmacol Sci 25, 177-181.

Jacobson MD, M Weil, MC Raff. 1997. Programmed cell death in animal development. Cell 88, 347-354.

Jansen R, G Burton. 2004. Mitochondrial dysfunction in reproduction. Mitochondrion 4, 577-600.

Jiménez M, C Vélez. 2002. Monoamine neurotoxins-induced apoptosis in lymphocytes by a common oxidative stress mechanism: involvement of hydrogen peroxide $\left(\mathrm{H}_{2} \mathrm{O}_{2}\right)$, caspase-3, and nuclear factor kappa-B (NFKB), p53, c-Jun transcription factors. Biochemical Pharmacology 63, 667-688.

Kerr J, A Wyllie, A Currie. 1972. Apoptosis: a basic biological phenomenon with wide-ranging implications in tissue kinetics. Br J Cancer 26, 239-257.

Kowaltowski A, R Castilho, A Vercesi. 2001. Mitochondrial permeability transition and oxidative stress. FEBS letters 495, 12-15.

Lane M, DK Gardner. 1998. Amino acids and vitamins prevent cultureinduced metabolic perturbations and associated loss of viability of mouse blastocysts. Human Reprod 13, 991-997.

Lequarre AS, J Marchandise, B Moreau, A Massip, I Donnay. 2003. Cell cycle duration at the time of maternal zygotic transition for in vitro produced bovine embryos: effect of oxygen tension and transcription inhibition. Biol Reprod 69, 1707-1713.

Little SA, PE Mirkes. 2002. Teratogen-induced activation of caspase-9 and the mitochondrial apoptotic pathway in early postimplantation mouse embryos. Toxicol Appl Pharmacol 181, 142-151.

Liu Y, G Fiskum, D Schubert. 2002. Generation of reactive oxygen species by the mitochondrial electron transport chain. J Neurochem 80, 780-787.

Lonergan P, A Adan, B Pintado, T Fair, F Ward, JD Fuente, M Boland. 2004. Relationship between time of first cleavage and the expresion of the IGF-1 growth factor, its receptor and two housekeeping genes in bovine two cell embryos and blastocyst produced in vitro. Mol Reprod Dev 57, 146-152.

Lu DP, L Tian, C O'Neill, NJ King. 2002. Regulation of cellular adhesion molecule expression in murine oocytes, peri-implantation and postimplantation embryos. Cell Res 12, 373-383.

Lu X. 2005. p53: a heavily dictated dictator of life and death. Curr Opin Genet Dev 15, 27-33.

Majno G, I Joris. 1995. Apoptosis, oncosis, and necrosis. An overview of cell death. Am J Pathol 146, 3-15.

Meirelles FV, AR Caetano, YF Watanabe, P Ripamonte, SF Carambula, GK Merighe, SM Garcia. 2004. Genome activation and developmental block in bovine embryos. Anim Reprod Sci 82, 13-20.

Memili E, NL First. 2000. Zygotic and embryonic gene expression in cow: a review of timing and mechanisms of early gene expression as compared with other species. Zygote 8, 87-96.

Milligan CE, LM Schwartz. 1997. Programmed cell death during animal development. Brit Med Bull 53, 570-590. 
Mostefai H, A Agouni, N Carusio, M Mastronardi, C Heymes, D Henrion, R Andriantsitohaina, C Martínez. 2008. Phosphatidylinositol 3-Kinase and xanthine oxidase regulate nitric oxide and reactive oxygen species productions by apoptotic lymphocyte microparticles in endothelial cells. The Journal of Immunology 180, 5028-5035.

Nishikimi A, J Mukai, M Yamada. 1999. Nuclear translocation of nuclear factor Kappa B in early 1-cell mouse embryos. Biol Reprod 60, 1536-1541.

Nohl H, L Gille, K Staniek. 2005. Intracellular generation of reactive oxygen species by mitochondria. Biochem Pharmacol 69, 719-723.

Parone P, D James, J Martinou. 2002. Mitochondria: regulating the inevitable. Biochimie 84,105-111.

Paula-Lopesa FF, PJ Hansen. 2002. Heat shock-induced apoptosis in preimplantation bovine embryos is a developmentally regulated phenomenon. Biol Reprod 66, 1169-1177.

Picton H, D Briggs, R Gosden. 1998. The molecular basis of oocyte growth and development. Mol Cell Endocrinol 145, 27-37.

Pomar F, K Teerds, A Kidson, B Colenbrander, T Tharasanit, B Aguilar, B Roelen. 2005. Differences in the incidence of apoptosis between in vivo and in vitro produced blastocysts of farm animal species: a comparative study. Theriogenology 63, 2254-2268.

Sardet Ch, F Prodon, G Prulière, J Chenevert. 2004. Polarisation des œufs et des embryons: principes communs. Médecine/Science 20, 414-423.

Serrano C, M Olivera-Angel. 2003. Detenimiento en el ciclo celular de embriones bovinos producidos in vitro. Taurus 5, 20-35.

Shishodia S, B Aggarwal. 2004. Nuclear factor-kB: a friend or a foe in cancer? Biochem Pharmacol 68, 1071-1080.

Stojkovic M, SA Machado, P Stojkovic, V Zakhartchenko, P Hutzler, PB Goncalves, E Wolf. 2001. Mitochondrial distribution and adenosine triphosphate content of bovine oocytes before and after in vitro maturation: correlation with morphological criteria and developmental capacity after in vitro fertilization and culture. Biol Reprod 64, 904-909.

Susin S, N Zamzami, G Kroemer. 1996. The cell biology of apoptosis: Evidence for the implication of mitochondria. Apoptosis 1, 231-242.

Takada Y, A Mukhopadhyay, G Kundu, G Mahabeleshwar, S Singh, B Aggarwal. 2003. Hydrogen peroxide activates NFאB through tyrosine phosphorylation of $\mathrm{IkB} \alpha$ and serine phosphorylation of p65. J Biol Chem 278, 24233-24241.

Tarazona AM, JI Rodríguez, LF Restrepo, M Olivera-Angel. 2006. Mitochondrial activity, distribution and segregation in bovine oocytes and in embryos produced in vitro. Reprod Dom Anim 41, 5-11.
Thompson JG, RJ Partridge, FD Houghton, CI Cox, HJ Leese. 1996. Oxigen uptake and carbohydrate metabolism by in vitro derived bovine embryos. J Reprod Fertil 106, 299-306.

Thompson JG, C McNaughton, B Gasparrini, LT McGowan, HR Tervit. 2000. Effect of inhibitors and uncouplers of oxidative phosphorylation during compaction and blastulation of bovine embryos cultured in vitro. J Reprod Fertil 118, 47-55.

Torchinsky A, V Toder. 2004. To die or not to die: the function of the transcription factor NF-kappaB in embryos exposed to stress. J Reprod Immunol 51, 138-143.

Trounson A, C Anderiesz, G Jones. 2001. Maturation of human oocytes in vitro and their developmental competence. Reproduction 121, 51-75.

Turcotte L. 2003. Mitochondria: biogenesis, structure, and functionSymposium introduction. Med Sci Sports Exerc 35, 82-85.

Van Blerkom J, P Davis, S Alexander. 2000. Differential mitochondrial distribution in human pronuclear embryos leads to disproportion. Hum Reprod 15, 2621-2633.

Van Blerkom J, P Davis, V Mathwing, S Alexander. 2002. Domains of high-polarized and low-polarized mitochondria may occur in mouse and human oocytes and early embryos. Hum Reprod 17, 393-406.

Vélez-Pardo C, A Morales, M Del Río, M Olivera-Angel. 2007. Endogenously generated hydrogen peroxide induces apoptosis via mitochondrial damage independent of NF-kB and $\mathrm{p} 53$ activation in bovine embryos. Theriogenology 67, 1285-1296.

Vousden KH, X Lu. 2002. Live or let die: the cell's response to p53. Nat Rev Cancer 2, 594-604.

Wang T, CA Lessman. 2002. Isoforms of soluble alpha-tubulin in oocytes and brain of the frog (genus Rana): changes during oocyte maturation. Cell Mol Life Sci 59, 2216-2223.

Wilding M, B Dale, M Marino, L di Matteo, C Alviggi, ML Pisaturo, L Lombardi, G De Placido. 2001. Mitochondrial aggregation patterns and activity in human oocytes and preimplantation embryos. Hum Reprod 16, 909-917.

Yang HW, KJ Hwang, HC Kwon, HS Kim, KW Choi, KS Oh. 1998. Detection of reactive oxygen species (ROS) and apoptosis in human fragmented embryos. Hum Reprod 13, 998-1002.

Zakeri Z, R Lockshin, L Criado-Rodríguez, C Martínez-A. 2005. A generalized caspase inhibitor disrupts early mammalian development. Int J Dev Biol 49, 43-51.

Zhou L, H Steller. 2003. Distinct pathways mediate UV-induced apoptosis in Drosophila embryos. Dev Cell 4, 599-605. 